\title{
IL6 induces TAM resistance via kinase-specific phosphorylation of ER $\alpha$ in OVCA cells
}

\author{
Yue Wang ${ }^{1,2}$, Xiu Long $\mathrm{Niu}^{3}$, Xiao Qin Guo ${ }^{2}$, Jing Yang ${ }^{2}$, Ling $\mathrm{Li}^{4}, \mathrm{Ye} \mathrm{Qu}^{2}$, Cun Xiu Hu${ }^{5}$, \\ Li Qun Mao ${ }^{2}$ and Dan Wang ${ }^{2}$ \\ ${ }^{1}$ Tianjin Key Laboratory for Prevention and Control of Occupational and Environmental Hazard, Tianjin, \\ People's Republic of China \\ ${ }^{2}$ Department of Pathogenic Biology and Immunology, Logistics College of Chinese People's Armed Police Forces, \\ Dongli District, Huizhi Ring Road, Number 1, Tianjin 300309, People's Republic of China \\ ${ }^{3}$ Department of Infectious Diseases, Affiliated Hospital of Logistics College of Chinese People's Armed Police Forces, \\ Tianjin, People's Republic of China \\ ${ }^{4}$ Department of Pharmacology, Logistics College of Chinese People's Armed Police Forces, Tianjin, \\ People's Republic of China \\ ${ }^{5}$ Department of Gynecology and Obstetrics, Affiliated Hospital of Logistics College of Chinese People's Armed Police \\ Forces, Tianjin, People's Republic of China
}

Correspondence should be addressed to $Y$ Wang

Email wangyue6808@126.com

\begin{abstract}
About $40-60 \%$ of ovarian cancer (OVCA) cases express ER $\alpha$, but only a small proportion of patients respond clinically to anti-estrogen treatment with estrogen receptor (ER) antagonist tamoxifen (TAM). The mechanism of TAM resistance in the course of OVCA progression remains unclear. However, IL6 plays a critical role in the development and progression of OVCA. Our recent results indicated that IL6 secreted by OVCA cells may promote the resistance of these cells to TAM via ER isoforms and steroid hormone receptor coactivator-1. Here we demonstrate that both exogenous (a relatively short period of treatment with recombinant IL6) and endogenous IL6 (generated as a result of transfection with a plasmid encoding sense IL6) increases expression of pER $\alpha$-Ser118 and pER $\alpha$-Ser167 in non-IL6-expressing A2780 cells, while deleting endogenous IL6 expression in IL6-overexpressing CAOV-3 cells (by transfection with a plasmid encoding antisense IL6) reduces expression of $\mathrm{pER} \alpha$-Ser118 and $\mathrm{pER} \alpha$-Ser167, indicating that IL6-induced TAM resistance may also be associated with increased expression of $p E R \alpha-\operatorname{Ser} 118$ and $p E R \alpha$-Ser 167 in OVCA cells. Results of further investigation indicate that IL6 phosphorylates ER $\alpha$ at Ser118 and Ser167 by triggering activation of MEK/ERK and phosphotidylinositol 3 kinase/Akt signaling, respectively, to activate the ER pathway and thereby induce OVCA cells resistance to TAM. These results indicate that IL6 secreted by OVCA cells may also contribute to the refractoriness of these cells to TAM via the crosstalk between ER and IL6-mediated intracellular signal transduction cascades. Overexpression of IL6 not only plays an important role in OVCA progression but also promotes TAM resistance. Our results indicate that TAMIL6-targeted adjunctive therapy may lead to a more effective intervention than TAM alone.
\end{abstract}

\author{
Key Words \\ - interleukin-6 (IL-6) \\ - tamoxifen(TAM) resistance \\ - kinase-specific \\ phosphorylation of Estrogen \\ receptor (ER) $\alpha$ \\ - ERK \\ - Akt \\ - ovarian cancer (OVCA)
}

Journal of Molecular Endocrinology (2015) 54, 351-361
(C) 2015 Society for Endocrinology Printed in Great Britain
Published by Bioscientifica Ltd 


\section{Introduction}

Ovarian cancer (OVCA) continues to be the most fatal gynecological cancer, with an estimated 5-year survival rate of only 50\% (Jemal et al. 2009). The mechanisms of ovarian carcinogenesis have not yet been elucidated but appear to be different from those of breast tumor progression. Indeed, about two-thirds of breast cancer patients with ER-positive tumors respond clinically to anti-estrogen treatment with the ER antagonist tamoxifen (TAM). About $40-60 \%$ of OVCAs express ER $\alpha$ (Rao \& Slotman 1991, Havrilesky et al. 2001), but only a small proportion of patients (ranging from 7 to 18\%) respond to TAM therapy (Hatch et al. 1991, Scambia et al. 1995). Results of several studies have highlighted an increased risk of OVCA in patients receiving longterm estrogen replacement therapy (Glud et al. 2004, Lacey et al. 2006, Beral et al. 2007, Rossing et al. 2007). Estrogen action is mediated by two receptors, $\operatorname{ER} \alpha$ and $\operatorname{ER} \beta$, which show distinct tissue distributions and functions (Ascenzi et al. 2006). Upon binding of estrogen to ER, nuclear ER activates transcription (genomic action) either by direct DNA binding to its own response elements in targeted gene promoters (classical mode) or by tethering to other transcription factors, such as the Fos/Jun activating protein 1 complex (nonclassical mode). Membrane ER activity (nongenomic action), through direct interaction with different signaling intermediates at the vicinity of the membrane, can lead to rapid induction of key growthfactor-dependent kinases, such as mitogen-activated protein or MEK/ERK and phosphotidylinositol 3 kinase (PI3K)/Akt pathways (Schiff et al. 2003). Results of recent studies have indicated that the G-protein-coupled ER (GPER) mediates the non-genomic signaling of estrogen in a variety of estrogen-related cancers including OVCA (Albanito et al. 2007, Yan et al. 2013). Ge et al. (2013) have reported that GPER activation might be PI3K/Akt-dependent in endometrial cancer cells.

Interleukin 6 (IL6), a known mediator of immunological and inflammatory events, was elevated in serum and peritoneal fluid of patients with OVCA; high levels of IL6 in body fluids were associated with poor prognosis and survival (Penson et al. 2000, Lane et al. 2011). Results of multiple studies indicate a pathogenic role of this cytokine in the malignant transformation, progression and chemotherapy resistance of OVCA (Syed et al. 2002, Nilsson et al. 2005, Rabinovich et al. 2007, Yang et al. 2009, Wang et al. 2010a, 2012). Recently, the results of our studies indicated that IL6 secreted by OVCA cells may contribute to the refractoriness of these cells to TAM via ER isoforms and steroid hormone receptor coactivator (SRC)-1 (Wang et al. 2014).
IL6 acts through a hexametric receptor, which contains the ligand-binding IL6 receptor $\alpha$ chain and the common cytokine receptor signal-transducing subunit gp130. The binding of IL6 to gp130 activates multiple signal transduction pathways such as JAK/STATs, MEK/ERK and PI3K/Akt pathways (Hirano et al. 1997). The crosstalk between membrane-ER-induced intracellular signal transduction cascades and IL6-induced signal transduction pathways may include MEK/ERK and PI3K/Akt pathways. The results of our previous work indicated that IL6 and 17ß-estradiol $\left(\mathrm{E}_{2}\right)$ modulated reciprocally to promote OVCA cell proliferation and thereby indicated that it might be mediated through common intracellular signaling pathways (Yang et al. 2009). Meanwhile, the results of numerous preclinical studies have indicated that de novo and/or acquired TAM resistance is associated with increased activities of ERK and Akt (Silva et al. 2007, Normanno et al. 2008). Indeed, in the case of ER, ERK (Kato et al. 1995) and Akt (Campbell et al. 2001) have been reported to activate the ER pathway by direct phosphorylation of ER $\alpha$ at serine 118 (pER $\alpha$-Ser118) and serine 167 (pER $\alpha$-Ser167) respectively in the activation function-1 (AF-1) domain, a region responsible for the transcriptional activity of ER in the absence of ligand. These two sites appear to be the most relevant sites with regard to breast cancer resistance to TAM (de Leeuw et al. 2011). Results of studies have indicated a correlation between either pER $\alpha$-Ser118 or pER $\alpha$-Ser167 and TAM resistance (Green \& Carroll 2007). Therefore, we hypothesized that one potential mechanism involving crosstalk between ER and IL6-induced intracellular signal transduction cascades, such as MEK/ERK and PI3K/Akt pathways, contributes to anti-estrogen resistance.

In this study, we investigated whether IL6 phosphorylates ER $\alpha$ at Ser118 and Ser167 by triggering activation of MEK/ERK and PI3K/Akt signaling respectively to activate the ER pathway and thereby induce resistance to TAM in human OVCA cells.

\section{Materials and methods}

\section{Cell lines and cell culture}

Human OVCA cell lines A2780, CAOV-3, SKOV-3 and ES-2 were obtained from the American Type Culture Collection (Manassas, VA, USA). A2780, SKOV-3 and ES-2 cells were cultured in phenol-red-free RPMI 1640 (Life Technologies, Inc.) containing $10 \%$ fetal bovine serum (FBS) (Life

Published by Bioscientifica Ltd 
Technologies, Inc.), CAOV-3 cells were grown in phenolred-free DMEM (Life Technologies, Inc.) with 15\% FBS.

Recombinant human IL6 (R\&D Systems, Minneapolis, MN, USA) was used to pretreat A2780 cells. The cells were cultured in the presence of exogenous IL6 $(50 \mathrm{ng} / \mathrm{ml})$ for 10 days. IL6 was added to the culture every 2 days (Wang et al. 2010a). After the pretreatment period, the cells (A2780/preIL6) were harvested, washed and replated in the presence of IL6, and their resistance to TAM (Sigma) was determined by the MTT assay.

\section{Cell transfection and generation of stable cell lines}

A2780 (in which no IL6 was detected in the supernatant) and CAOV-3 cells (in which the secretion level of IL6 is 15 $873.47 \pm 620.52 \mathrm{pg} / \mathrm{ml}$ ) were transfected with pcDNA3.1 (+)-ssIL6 (i.e., sense IL6 vector) and pcDNA3.1(+)-asIL6 (i.e., antisense IL6 vector) by Lipofectamine2000 (Invitrogen), respectively. Two stable A2780/ssIL6 cell lines that produced moderate $(58.22 \pm 5.78 \mathrm{pg} / \mathrm{ml}$, A2780/ssIL6M) and high $(106.18 \pm 12.32 \mathrm{pg} / \mathrm{ml}, \mathrm{A} 2780 / \mathrm{ss} I L 6 \mathrm{H})$ levels of IL6 and two stable CAOV-3/asIL6 cell lines that displayed moderate (63.82\%, CAOV-3/asIL6Mi) and high (75.69\%, CAOV-3/asIL6Hi) inhibition of IL6 production were cloned as described previously (Wang et al. 2010a, 2014).

\section{Western blot analysis}

Analysis and quantitation were performed as previously described (Wang et al. 2010a). In brief, $100 \mu \mathrm{g}$ of total cell lysates were subjected to 10\% SDS-PAGE and analyzed by blotting with rabbit polyclonal anti-pER $\alpha$-Ser118, anti-pER $\alpha$-Ser167 or anti-ER $\alpha$ antibody (Santa Cruz Biotechnology) respectively. Membranes were stripped by incubation with stripping buffer at $50^{\circ} \mathrm{C}$ for $30 \mathrm{~min}$ and then blotted with mouse monoclonal anti- $\beta$-actin antibody (Sigma). Immunodetection was performed using the corresponding secondary HRP-conjugated antibody, and HRP activity was detected using a chemiluminescent substrate kit (SuperSignal Westpico Trial Kit, Pierce Biochemicals, Rockford, IL, USA). The pER $\alpha$-Ser118:total $\mathrm{ER} \alpha$ and $\mathrm{pER} \alpha-$ Ser167:total ER $\alpha$ density ratios were determined and the data shown is the average of three independent experiments for the pER $\alpha$-Ser118:total ER $\alpha$ or pER $\alpha$-Ser167:total ER $\alpha$.

A2780 cells were pretreated in 1\% charcoal-stripped FBS (sFBS) (Hyclone Laboratories, Inc., Logan, UT, USA) with vehicle DMSO (Sigma), or the MEK1/2 inhibitor PD98059 (25 or $50 \mu \mathrm{M})$, or the PI3K inhibitor wortmannin (100 or $200 \mathrm{nM}$ ) (Calbiochem, San Diego, CA, USA) for $30 \mathrm{~min}$ prior to addition of $50 \mathrm{ng} / \mathrm{ml}$ IL6 or $10 \mathrm{nM} E_{2}$
(Sigma) for $6 \mathrm{~h}$. Total cell lysates were isolated and quantified. The phosphorylation status of endogenous ERK, Akt and ER $\alpha$ was analyzed by western blotting as described above, except that the filters were probed with antibodies against phospho-Akt or phospho-ERK (Cell Signaling Technology, Beverly, MA, USA) to detect phosphorylated ERK or Akt. The filters were subsequently stripped and then reprobed with antibodies against ERK (BD Biosciences, San Diego, CA, USA) or Akt (Cell Signaling Technology) to detect both the phosphorylated and unphosphorylated forms of ERK or Akt.

\section{Cytotoxicity assay}

In vitro cytotoxicity assays were performed by MTT assay, with MTT obtained from Sigma. Briefly, $4 \times 10^{3}$ cells/well were plated into 96-well plates for $24 \mathrm{~h}$, and then switched to medium containing $1 \%$ sFBS and cultured for another $24 \mathrm{~h}$. The cells were pretreated with different concentrations $(0.1,1,10,100$ or $1000 \mathrm{nM})$ of TAM in DMSO for 30 min before $1 \mathrm{nM} \mathrm{E}_{2}$ was added into the medium. After $48 \mathrm{~h}$ in culture, MTT solution $(0.5 \mathrm{mg} / \mathrm{ml} \mathrm{PBS})$ was added to each well and incubated for $4 \mathrm{~h}$. After dissolving the resulting formazan product with acid-isopropanol, the absorbance was measured at $490 \mathrm{~nm}$ using an ELISA microplate reader. Data represents the average absorbance of six wells in one experiment. The percentage of surviving cells was estimated by dividing the $\mathrm{A}_{490} \mathrm{~nm}$ of treated cells by the $\mathrm{A}_{490} \mathrm{~nm}$ of control cells. Data were derived from at least three independent experiments.

A2780 cells pretreated with IL6 (A2780/preIL6) and ssIL6transfected A2780 cells that produced high levels of IL6 (A2780/ssIL6H) were treated as described above, except that cells were incubated in $1 \%$ sFBS with PD98059 ( 25 or $50 \mu \mathrm{M})$, wortmannin (100 or $200 \mathrm{nM}$ ), or vehicle DMSO for $30 \mathrm{~min}$ prior to administration of TAM $(1000 \mathrm{nM})$ and $\mathrm{E}_{2}(1 \mathrm{nM})$.

\section{Transient transfection and luciferase reporter assay}

Transfection was done using Lipofectamine2000 (Invitrogen) according to the instructions of the manufacturer. Cells were plated onto 12-well plates until 90-95\% confluency before transfection. A2780 and CAOV-3 cells and their stable transfectants were transfected with $2 \mu \mathrm{g}$ DNA containing the luciferase reporter gene linked to two copies of the consensus ERE cloned upstream of the minimal herpes simplex virus thymidine kinase promoter (ERE2-TK-Luc), which was kindly provided by Dr Gwendal Lazennec (Unite' INSERM 540, Montpellier, France), and $1 \mu \mathrm{g}$ of $\beta$-galactosidase DNA to evaluate transfection efficiency.

Published by Bioscientifica Ltd 
After $24 \mathrm{~h}$, the cells were treated in 1\% sFBS with IL6 $(5,25$ or $50 \mathrm{ng} / \mathrm{ml}$ ) for $24 \mathrm{~h}$. Cells were lysed and luciferase activities were measured using the Luciferase Assay System (Promega) and captured by Thermo Fluoroskan Ascent FL (Thermo Electron Corporation, Beverley, MA, USA). $\beta$-galactosidase activities were detected using ONPG substrate (Sigma), and measured at $420 \mathrm{~nm}$ using an ELISA microplate reader. The luciferase values were normalized to $\beta$-galactosidase activity and presented as the mean relative luciferase activity of three independent experiments.

A2780 cells and ssIL6-transfected A2780 cells (A2780/ssIL6H) were treated as described above, except that the cells were pretreated in 1\% sFBS with ICI 182780 $(100 \mu \mathrm{M})$ (Sigma), PD98059 $(50 \mu \mathrm{M})$, wortmannin $(200 \mathrm{nM})$ or DMSO of equal volume for $30 \mathrm{~min}$ at $37^{\circ} \mathrm{C}$ before treatment with IL6 $(25 \mathrm{ng} / \mathrm{ml}$, in A2780 cells).

\section{Statistical analysis}

Multiple comparisons were performed using two-way ANOVA with multiple post-hoc comparisons. All statistical tests were two-sided. For all tests, the level of significance was set at $P<0.05$. Statistical analysis was done using the SPSS version 11.0 Software.

\section{Results}

Comparing sensitivity to TAM and expression levels of IL6 as well as the status of $p E R \alpha-S e r 118$ and $p E R \alpha-S e r 167$ in four OVCA cell lines

The results of our previous work indicated that high, moderate and low levels of IL6 expression were observed in CAOV-3, SKOV-3 and ES-2 cells respectively, while no IL6 was detected in A2780 cells (Wang et al. 2010a). Also, we found that A2780 and ES-2 cells expressed low and moderate levels of $p E R \alpha$-Ser 118 and $p E R \alpha$-Ser 167 respectively, whereas CAOV-3 and SKOV-3 cells expressed high levels of pER $\alpha$ Ser118 and pER $\alpha$-Ser167 (Wang et al. 2010b). As shown in Fig. 1, sensitivity to TAM was different but consistent with expression levels of IL6 as well as the status of pER $\alpha$-Ser118 and pER $\alpha$-Ser167 in the four types of OVCA cells. A2780 cells were the most sensitive to TAM, after which came ES-2 cells, whereas CAOV-3 and SKOV-3 cells were drug-resistant.

\section{IL6 enhances expression of pER $\alpha$-Ser118 and pER $\alpha$-Ser167 and contributes to TAM resistance in OVCA cells}

The results described in the previous section indicated that the status of $\mathrm{pER} \alpha$-Ser118 and pER $\alpha$-Ser167 was consistent

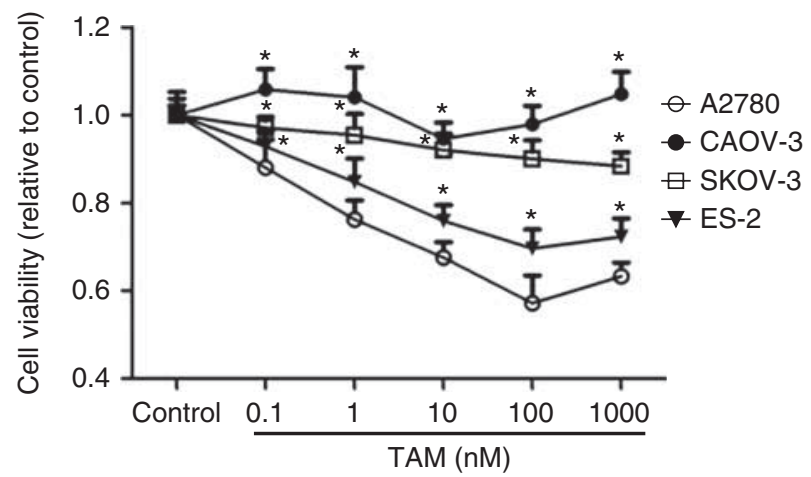

Figure 1

Differences in sensitivity to TAM of A2780, CAOV-3, SKOV-3 and ES- 2 cells were assessed by the MTT assay. Data are shown as the mean \pm s.D. of three separate experiments with six iterations. ${ }^{*} P<0.05$, compared with A2780 cells.

with expression levels of IL6 in four OVCA cells. To determine whether IL6 phosphorylates ER $\alpha$ at Ser118 and Ser167, we examined expression levels of pER $\alpha$-Ser118 and pER $\alpha$-Ser167 in A2780 cells treated with IL6, ss/asIL6transfected cells and the corresponding untransfected and control-vector-transfected cells by western blot analysis. IL6 significantly increased expression levels of pER $\alpha$ Ser118 and pER $\alpha$-Ser167 in a dose-dependent manner in A2780 cells (Fig. 2A). Expression levels of p-ER118 and p-ER167 were upregulated in ssIL6-transfected A2780 cells (Fig. 2B), and downregulated in asIL6-transfected CAOV-3 cells (Fig. 2C) compared with the corresponding untransfected and control-vector-transfected cells, which did not vary. These results indicate that IL6 increases the expression of pER $\alpha$-Ser118 and pER $\alpha$-Ser167 in OVCA cells. Results of our previous study have indicated that IL6 confers TAM resistance in OVCA cells (Wang et al. 2014). Together, these results indicate that IL6-induced TAM resistance may be associated with increased expression of pER $\alpha$-Ser118 and pER $\alpha$-Ser167 in OVCA cells.

\section{IL6 signaling involves the MEK/ERK and PI3K/Akt pathways in mediating TAM resistance of OVCA cells}

IL6 signal transduction involves several major phosphorylation cascades, including the MEK/ERK and PI3K/Akt pathways (Hirano et al. 1997). To confirm canonical IL6 signal transduction in the cell lines used, the activity of the downstream kinases ERK and Akt was determined by western blot analysis. It was found that PD98059, a MEK1/2-specific inhibitor at 25 or $50 \mu \mathrm{M}$, and wortmannin, a PI3K-specific inhibitor at 100 or $200 \mathrm{nM}$,

Published by Bioscientifica Ltd 

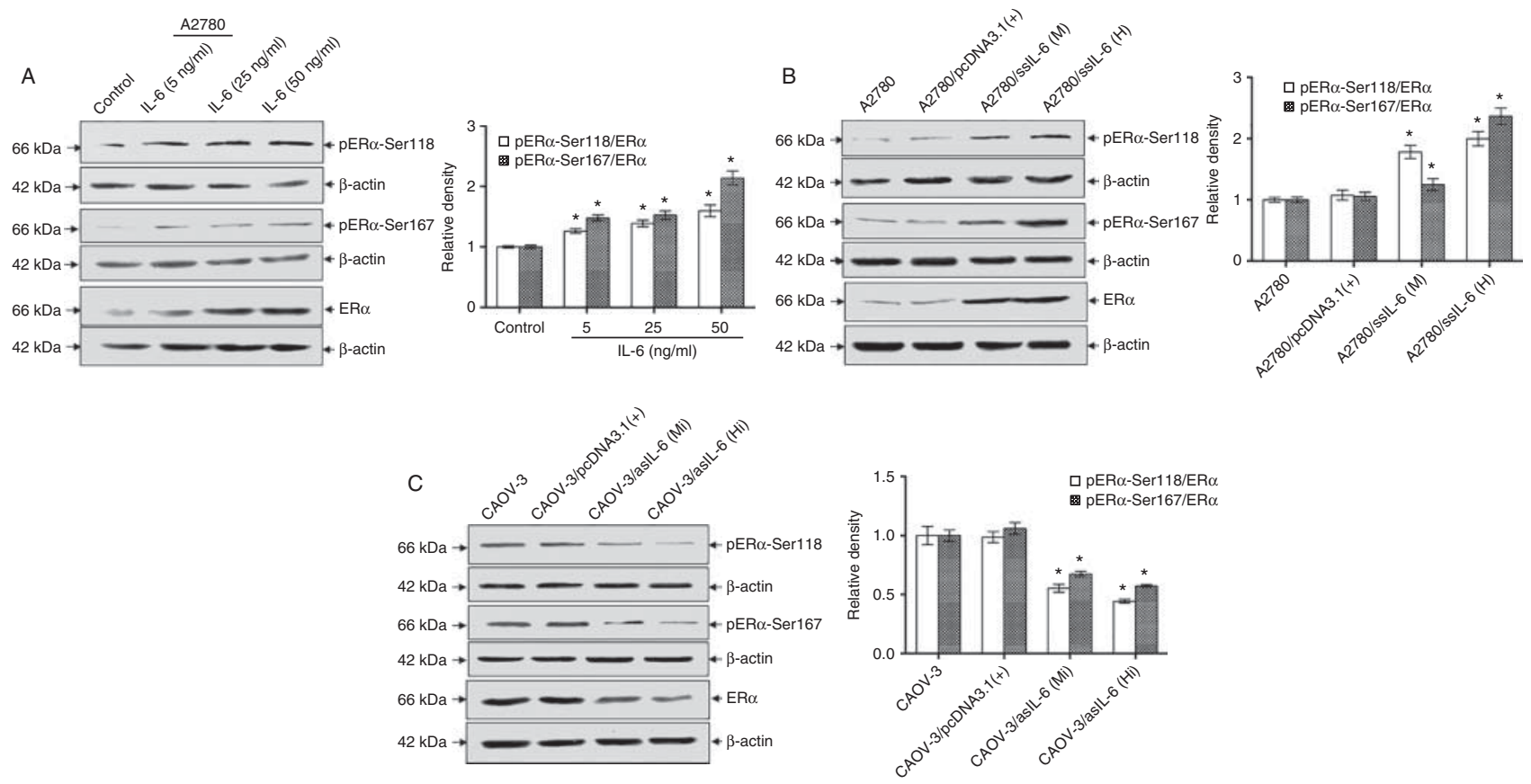

\section{Figure 2}

IL6 enhances expression of $p E R \alpha$-Ser 118 and $p E R \alpha$-Ser167 and contributes to TAM resistance in OVCA cells. (A) Exogenous IL6 increases expression levels of $p E R \alpha$-Ser118 and $p E R \alpha$-Ser167 in A2780 cells. Expression levels of pER $\alpha$-Ser 118 and $p E R \alpha$-Ser 167 in two stable ssIL6-transfected A2780 clones (B), two asIL6-transfected CAOV-3 clones (C), and the corresponding parental and vector control cells. Expression levels of $p E R \alpha-S e r 118$,

significantly antagonized IL6-induced phosphorylation of ERK and Akt respectively (Fig. 3A and B), and both of them blocked IL6-induced TAM resistance (Fig. 4A) while the inhibitory effects of PD98059 and wortmannin were dependent on concentration.

In correlation with data from A2780 cells treated with IL6, ssIL6-transfected A2780 cells increased basal phosphorylation of ERK and Akt respectively, whereas asIL6transfected CAOV-3 cells decreased compared with the corresponding control cells (Fig. 3C). Similarly, we also found that PD98059 and wortmannin significantly abolished IL6-induced TAM resistance of ssIL6-transfected A2780 cells, A2780/ssIL6H (Fig. 4B). These results confirm that IL6 signaling involves the MEK/ERK and PI3K/Akt pathways to mediate TAM resistance of OVCA cells.

\section{IL6 phosphorylates ER $\alpha$ at Ser118 and Ser167 in OVCA cells by triggering activation of MEK/ERK and PI3K/Akt signaling, respectively}

Results of previous studies have indicated that phosphorylation of ER $\alpha$ by serine/threonine protein kinases induces
pER $\alpha$-Ser167 and total ER $\alpha$ were detected by western blotting, as described in the Materials and methods. The pER $\alpha$-Ser118/total ER $\alpha$ and $\mathrm{pER} \alpha$ Ser167/total ER $\alpha$ density ratios were determined and the data shown is average of three independent experiments for the $\mathrm{pER} \alpha$-Ser118:total ER $\alpha$ or $p E R \alpha-S e r 167:$ total ER $\alpha .{ }^{*} P<0.05$, compared with vehicle control or the parental A2780 or CAOV-3 cells.

TAM resistance (Kato et al. 1995, Campbell et al. 2001, Park et al. 2005, Yamashita et al. 2005, Likhite et al. 2006, Yamnik et al. 2009, Guo et al. 2010, de Leeuw et al. 2011). Ser118 and Ser-167 are two of the most reported phosphorylation sites of ER $\alpha$. These two sites are phosphorylated by ERK and Akt respectively (Kato et al. 1995, Campbell et al. 2001). Upstream, the MEK/ERK and PI3K/Akt signaling routes can be activated by IL6 stimulation (Hirano et al. 1997). Therefore, we next examined whether IL6 phosphorylates $\mathrm{ER} \alpha$ at Ser-118 and Ser-167 by triggering activation of MEK/ERK and PI3K/Akt signaling respectively. As shown in Fig. 5A and B, the MEK1/2-specific inhibitor PD98059 and the PI3K-specific inhibitor wortmannin markedly blocked IL6-induced pER $\alpha$-Ser118 and pER $\alpha$-Ser167, respectively. Similar results with IL6 on pER $\alpha$-Ser118 and pER $\alpha$ Ser167 were also observed after $\mathrm{E}_{2}$ exposure, and the effects of $\mathrm{E}_{2}$ on pER $\alpha$-Ser118 and pER $\alpha$-Ser167 were blocked by PD98059 and wortmannin respectively (Fig. 5A and B). Collectively, these results indicate that both IL6 and estrogen can phosphorylate ER $\alpha$ at Ser-118 and Ser-167 by triggering activation of MEK/ERK and PI3K/Akt signaling respectively.

Published by Bioscientifica Ltd. 
A

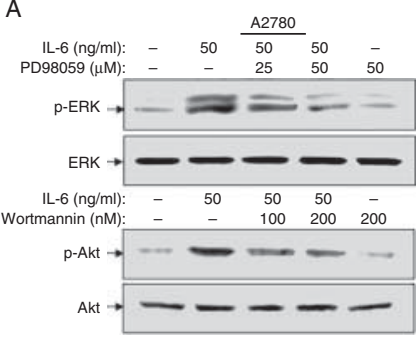

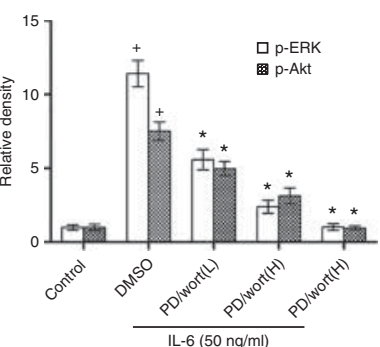

C

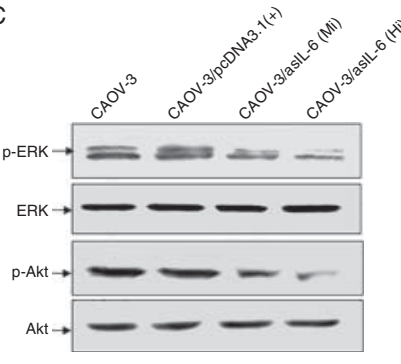

B
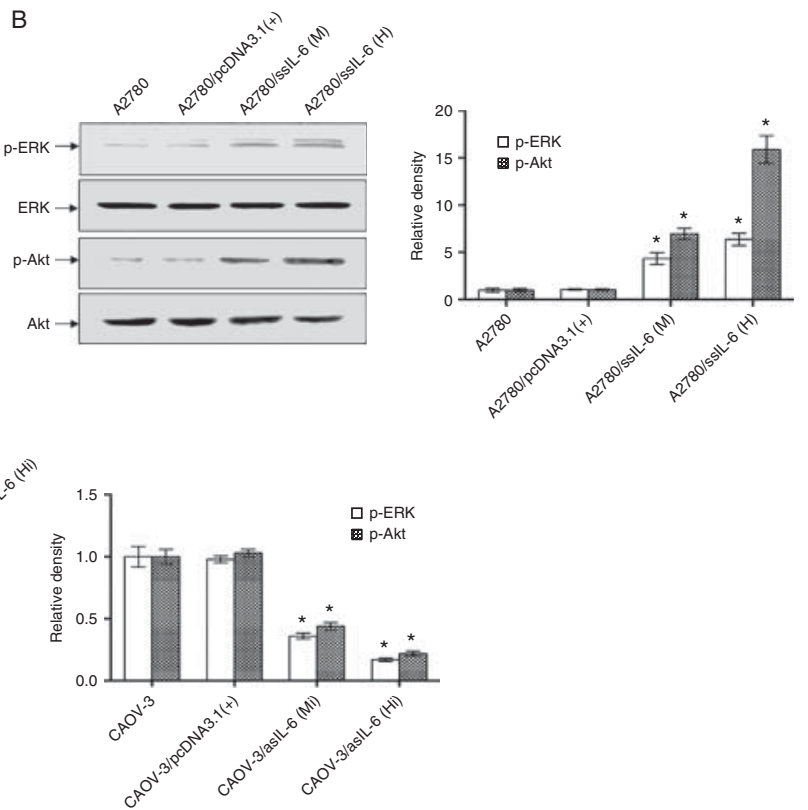

Figure 3

Effects of PD98059 or wortmannin on IL6-induced phosphorylation of ERK or Akt in A2780 cells (A). A2780 cells were pretreated with PD98059 (25 or $50 \mu \mathrm{M})$, wortmannin ( 100 or $200 \mathrm{nM}$ ) or DMSO of equal volume for $30 \mathrm{~min}$ at $37^{\circ} \mathrm{C}$ before IL 6 was added into the medium for $6 \mathrm{~h}$. After the cells were collected and washed, whole-cell extracts were prepared and subjected to western blot assay. ${ }^{+} P<0.05$, compared with vehicle control; ${ }^{*} P<0.05$,

\section{IL6 induces ER $\alpha$ transactivation activity in OVCA cells via ER-dependent MEK/ERK but not PI3K/Akt activation}

Next, we further assessed whether IL6 induces ER $\alpha$ transactivation activity and, if present, whether the activation depends on the MEK/ERK and PI3K/Akt pathways. After transfection with ERE2-TK-Luc plasmids, A2780 cells were treated in 1\% sFBS with IL6. Figure 6A shows data indicating that IL6 induced ER $\alpha$ transactivation activity in a dose-dependent manner (Fig. 6A), and this activation was blocked by the pure ER antagonist ICI 182 780, and the MEK1/2 inhibitor PD98059 but not the PI3K-specific inhibitor wortmannin (Fig. 6B). Consistent with results from A2780 cells treated with IL6, there was a significantly increased level of $\mathrm{ER} \alpha$ transactivation activity in ssIL6-transfected A2780 cells (Fig. 6C) as compared with the corresponding controls. Also, we found that ICI 182780 and PD98059 significantly inhibited the ER $\alpha$ transactivation activity of IL6-overexpressing A2780 cells compared with those of control cells, while wortmannin did not (Fig. 6D). Taken together, these results indicate that IL6 induces $\mathrm{ER} \alpha$ transactivation activity in OVCA cells via ER-dependent MEK/ERK but not PI3K/Akt activation. compared with IL6 alone. Effects of IL6 expression on ERK and Akt activities in OVCA cells ( $B$ and C). Western blot analysis of the phosphorylation status of ERK and Akt in A2780 and CAOV-3 cells and their transfectants. ${ }^{*} P<0.05$, compared with the parental A2780 or CAOV-3 cells. The data shown is average of three independent experiments with similar results.

\section{Discussion}

The potential mechanisms for TAM resistance in the course of OVCA progression are still poorly understood. Preclinical and clinical evidence indicates that growth factor signal transduction pathways may contribute to TAM resistance. Both the ER $\alpha$ and growth factor signal transduction pathway act in crosstalk. The membrane ER $\alpha$ activates surface tyrosine kinase receptors such as the epidermal growth factor receptor (EGFR), the human EGFR2 (HER2) and the insulin-like growth factor 1 receptor (IGF1R), and interacts with cellular kinases and adaptor molecules such as c-Src or the p85 $\alpha$ regulatory subunit of PI3K, which lead to the activation of ERK and Akt pathways known to increase cell proliferation and survival; in turn, this can phosphorylate ER $\alpha$ and/or its coregulators (Arnold et al. 1995, Joel et al. 1998a, Park et al. 2005, Massarweh \& Schiff 2006, Jordan \& O'Malley 2007). In addition, clinical data indicate that TAM-resistant breast cancers often exhibit an increased expression of growth factor receptors (e.g. EGFR, HER2, and IGF1R) (Gee et al. 2005, Nicholson et al. 2007, Moerkens et al. 2014). In addition, increased activation of their downstream targets ERK and PI3K/Akt leading to increased pER $\alpha$-Ser118

Published by Bioscientifica Ltd 

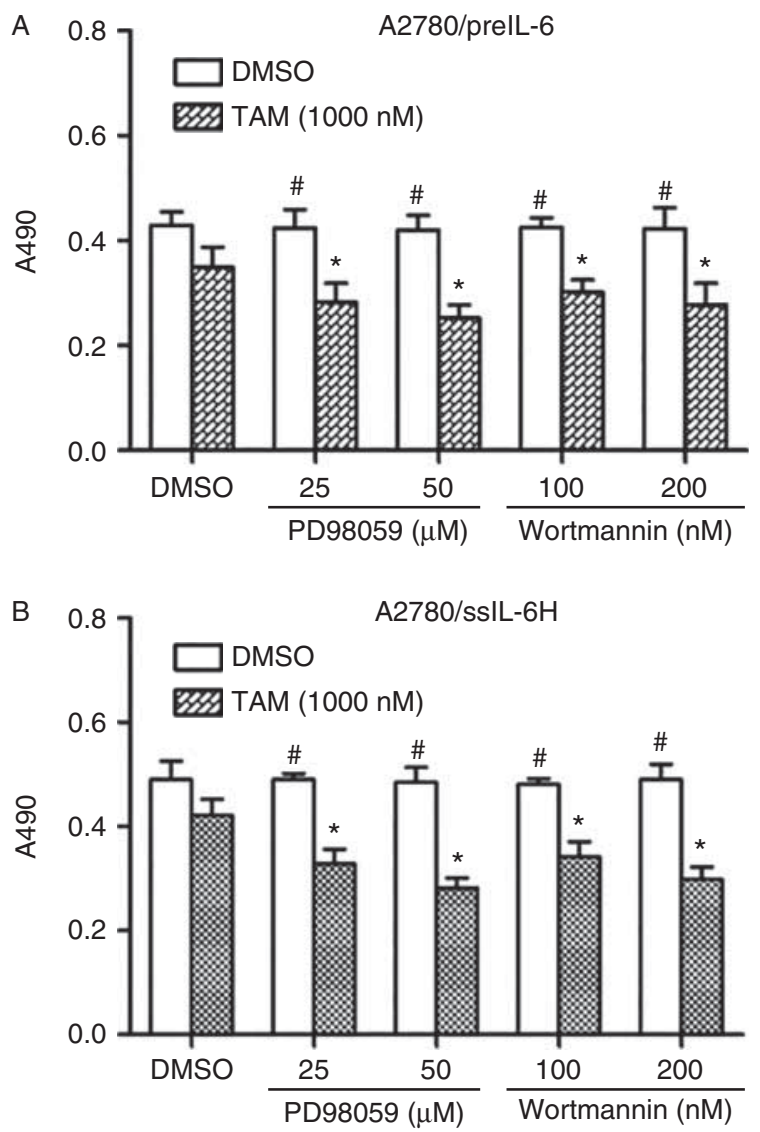

Figure 4

IL6-mediated TAM resistance in OVCA cells was blocked by PD98059 or wortmannin. A2780 cells pretreated with IL6 (A2780/prelL6) and ssIL6transfected A2780 cells (A2780/ssIL6H) were seeded into 96-well plates $\left(4 \times 10^{4}\right.$ cells/well). PD98059 $(25$ or $50 \mu \mathrm{M})$, wortmannin $(100$ or $200 \mathrm{nM})$ or DMSO was added 30 min before treatment in $1 \%$ sFBS with TAM (1000 nM) and $\mathrm{E}_{2}(1 \mathrm{nM})$. In vitro cytotoxicity assays were performed by MTT assay as described in the materials and methods. The experiment shown is representative of three independent experiments with similar results. ${ }^{\#} P>0.05$, compared with vehicle control; ${ }^{*} P<0.05$, compared with TAM (no inhibitors).

and/or pER $\alpha$-Ser167 have been observed (Gee et al. 2001, Yamashita et al. 2005, Sarwar et al. 2006).

It has been widely reported that IL6 plays a critical role in the development and progression of OVCA (Syed et al. 2002, Nilsson et al. 2005, Rabinovich et al. 2007, Yang et al. 2009, Wang et al. 2012). Recent results from our group indicated that IL6 secreted by OVCA cells may contribute to the refractoriness of these cells to TAM via ER isoforms and SRC-1 (Wang et al. 2014). In this study, we investigated another potential mechanism involved in IL6-mediated TAM resistance in OVCA cells. We previously showed that the expression levels of IL6 were consistent with the status of pER $\alpha$-Ser118 and pER $\alpha$ Ser167 in four OVCA cell lines, including A2780, CAOV-3, SKOV-3 and ES-2 (Wang et al. 2010a,b). Here we first demonstrated that sensitivity to TAM was consistent with expression levels of IL6 as well as the status of $\mathrm{pER} \alpha$-Ser118 and pER $\alpha$-Ser167 in four OVCA cells. Subsequently, we demonstrated that both exogenous (a relatively short period of treatment with recombinant IL6) and endogenous IL6 (as a result of transfection with plasmid encoding sense IL6) enhance expression of pER $\alpha$-Ser118:total ER $\alpha$ and pER $\alpha$-Ser167:total ER $\alpha$ in non-IL6-expressing A2780 cells, while deleting the endogenous IL6 expression in IL6-overexpressing CAOV3 cells (due to transfection with plasmid encoding antisense IL6) reduces expression of pER $\alpha$-Ser118:total ER $\alpha$ and pER $\alpha$-Ser167:total ER $\alpha$. Phosphorylation of $\mathrm{ER} \alpha$-Ser118 and ER $\alpha$-Ser167 are two sites which have been shown to be involved in TAM resistance (Sarwar et al. 2006, Yamashita et al. 2008, Yamnik et al. 2009, Guo et al. 2010); we recently showed that there was a significantly increased resistance to TAM in A2780 cells pretreated with IL6 (A2780/preIL6) and ssIL6-transfected A2780 cells and a markedly increased responsiveness to TAM in asIL6-transfected CAOV-3 cells as compared with the corresponding control cells (Wang et al. 2014). These findings indicate that IL6-induced TAM resistance may also be associated with increased expression of $\mathrm{pER} \alpha$ Ser118 and pER $\alpha$-Ser167 in OVCA cells.

It has been demonstrated that $\mathrm{ER} \alpha$ may be phosphorylated on multiple amino acid residues (de Leeuw et al. 2011). $\mathrm{ER} \alpha$ has an N-terminal domain with a hormone-independent transcriptional activation function (AF-1, amino acids 1-180), a central DNA-binding domain (amino acids 181263) and a C-terminal ligand-binding domain with a hormone-dependent transcriptional activation function (AF-2; amino acids 302-552). Because both Ser-118 and Ser-167 are located in the AF-1 region, activation of ER $\alpha$ by phosphorylation of these two sites is ligand-independent. Ser-118 is perhaps the best-studied site of ER $\alpha$ phosphorylation and is widely considered to be a target of ERK, although other kinases such as the glycogen synthase kinse-3 (GSK-3), inhibitor of kappa B kinase (IKK) $\alpha$, cyclin-dependent kinase 7 (CDK7) and mammalian target of rapamycin (mTOR)/ ribosomal protein S6 kinase (p70S6K) may also phosphorylate this site (de Leeuw et al. 2011). Phosphorylation of ER $\alpha$-Ser118 by ERK increases binding of coactivator SRC-3 (Likhite et al. 2006) and renders ER $\alpha$ hypersensitive to $\mathrm{E}_{2}$ (Vendrell et al. 2005). Phosphorylation of ER $\alpha$-Ser118 decreases ER $\alpha$ affinity for TAM and reduces binding to DNA, when ER $\alpha$ is TAM-bound (Likhite et al. 2006). In a TAM-resistant cell line obtained by selection after prolonged exposure to TAM, ERK activity was found to be elevated and pER $\alpha$-Ser118 was increased (Vendrell et al. 2005). Upstream,

Published by Bioscientifica Ltd. 
A

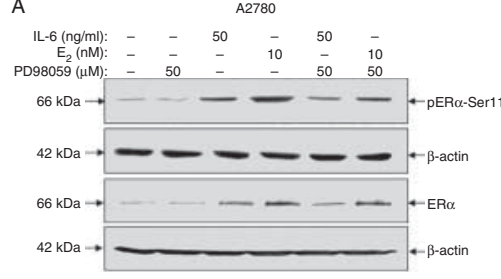

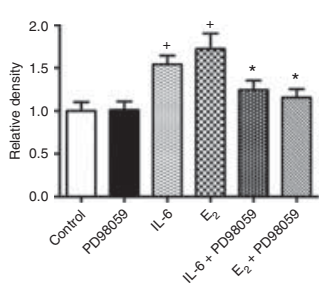

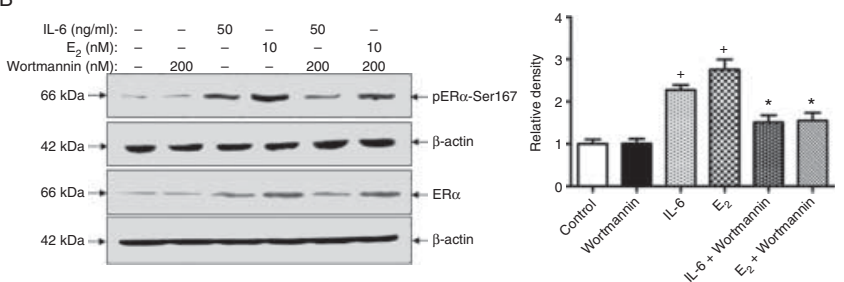

Figure 5

Effects of PD98059 or wortmannin on IL6-induced pER $\alpha$-Ser118 or pER $\alpha$ Ser167 in A2780 cells. A2780 cells were pretreated with PD98059 $(50 \mu \mathrm{M})$ wortmannin $(200 \mathrm{nM})$, or vehicle DMSO for $30 \mathrm{~min}$ prior to stimulation with IL6 $(50 \mathrm{ng} / \mathrm{ml})$ or $E_{2}(10 \mathrm{nM})$ for $6 \mathrm{~h}$. The expression levels of $p E R \alpha-$ Ser118, pER $\alpha$-Ser167 and total ER $\alpha$ were detected by western blotting as

the Ras/MEK/ERK pathway can be activated by IGF stimulation inducing pER $\alpha$-Ser118 and resulting in ER $\alpha$ activation and enhanced response to $\mathrm{E}_{2}$ (Kato et al. 1995). pER $\alpha$-Ser118 influences the recruitment of coregulators to $\mathrm{ER} \alpha$-regulated genes pS2, c-myc and cyclin D1 and affects E2induced gene expression (Duplessis et al. 2011). Ser-167 is phosphorylated by Akt, p90 ribosomal S6 kinase (p90RSK) and $\mathrm{mTOR} / \mathrm{p} 70 \mathrm{S6K}$ (de Leeuw et al. 2011). Akt is induced by EGF and IGF (Martin et al. 2000). Overexpression of either EGFR or Akt increases pER $\alpha$-Ser167 and reduces TAM sensitivity, whereas RNAi-mediated inhibition of Akt abrogates pER $\alpha$-Ser167 and restores TAM sensitivity (Glaros et al. 2006). In vitro, Akt-mediated pER $\alpha$-Ser167 can increase
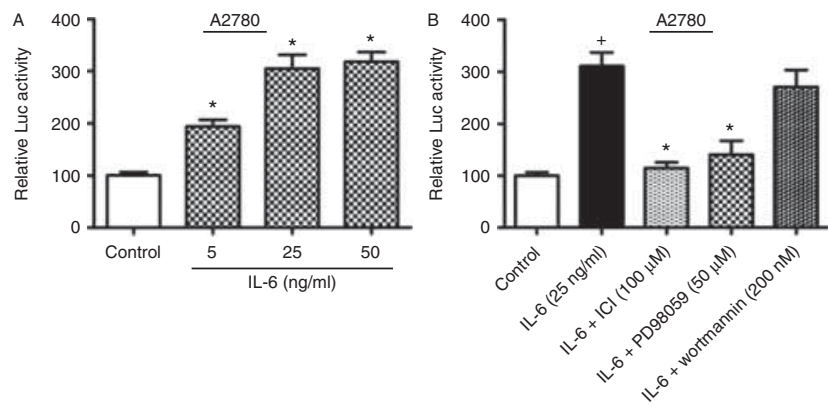

\section{Figure 6}

IL6 induces ER $\alpha$ transactivation activity in OVCA cells via ER-dependent MEK/ERK but not PI3K/Akt activation. (A) IL6 activates ER $\alpha$ in A2780 cells. ERE2-TK-Luc and $\beta$-galactosidase vector were transfected into A2780 cells as indicated, and then treated in $1 \%$ sFBS with IL6 $(0,5,25$ or $50 \mathrm{ng} / \mathrm{ml})$ for $24 \mathrm{~h}$. $\beta$-galactosidase and luciferase values were measured. $* P<0.05$, compared with vehicle control. (B) IL6-induced ER $\alpha$ transactivation activity was blocked by ER antagonist and specific inhibitors of related signal transducers. After transfection with ERE2-TK-Luc plasmids, the A2780 cells was incubated in $1 \%$ sFBS with ICI $182780(100 \mu \mathrm{M})$, PD98059 $(50 \mu \mathrm{M})$, wortmannin $(200 \mathrm{nM})$ or DMSO for 30 min prior to stimulation with $25 \mathrm{ng} / \mathrm{ml} \mathrm{IL6}$ for $24 \mathrm{~h}$. Total protein was then collected using lysis buffer and luciferase activities were measured as described above. ${ }^{+} P<0.05$ compared with vehicle control; $* P<0.05$, compared with IL6 alone. (C) Effect of IL6 described in the Materials and methods. The pER $\alpha$-Ser118:total ER $\alpha$ and $\mathrm{pER} \alpha$-Ser167:total ER $\alpha$ density ratios were determined and the data shown is average of three independent experiments for the $p E R \alpha$-Ser118:total ER $\alpha$ or pER $\alpha$-Ser167: total ER $\alpha .{ }^{+} P<0.05$, compared with vehicle control; ${ }^{*} P<0.05$, compared with IL6 or $E_{2}$ alone.

ER binding to DNA and increases the interaction of ER with the coactivator SRC-3 in the presence of estrogen (Likhite et al. 2006). Ser-167 is also targeted by other kinases such as ERK (Yamashita et al. 2005). We further demonstrated in this report that IL6 phosphorylates ER $\alpha$ at Ser-118 and Ser-167 by triggering activation of MEK/ERK and PI3K/Akt signaling respectively to activate the ER pathway and thereby induce OVCA cells' resistance to TAM. These results provide a novel mechanism in which IL6 secreted by OVCA cells may contribute to the refractoriness of these cells to TAM via the crosstalk between ER $\alpha$ and IL6-mediated intracellular signal transduction cascades. We also found that $\mathrm{E}_{2}$-induced $\mathrm{pER} \alpha$ Ser118 is dependent on the MEK/ERK signaling. This finding

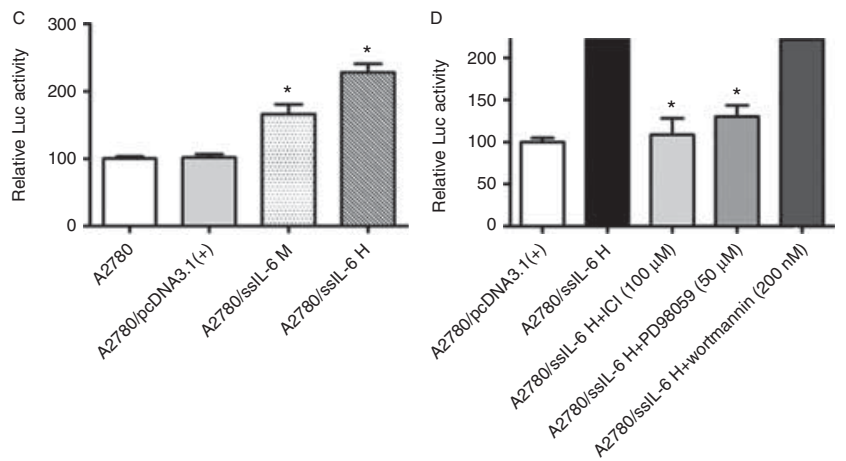

overexpression on $\mathrm{ER} \alpha$ transactivation activity in A2780 cells. Luciferase reporter assays in A2780 and their transfectants were performed as described in the Materials and methods. ${ }^{*} P<0.05$, compared with the parental A2780 cells. (D) Effects of ER antagonist and specific inhibitors of related signal transducers on $\mathrm{ER} \alpha$ transactivation activity in IL6-overexpressing A2780 cells. ssIL6-transfected A2780 cells (A2780/ssIL6H) were treated as described in the Materials and methods, except that cells were pretreated in $1 \%$ sFBS with ICI $182780(100 \mu \mathrm{M})$, PD98059 $(50 \mu \mathrm{M})$, wortmannin $(200 \mathrm{nM})$ or DMSO of equal volume for $30 \mathrm{~min}$ at $37^{\circ} \mathrm{C}$. ${ }^{+} P<0.05$, compared with vehicle (no inhibitors) of A2780/pcDNA3.1( + ) cells; $* P<0.05$, compared with vehicle (no inhibitors) of A2780/ssIL6H cells. The experiments shown are representative of three independent experiments with similar results.

Published by Bioscientifica Ltd. 
is similar to that of Cheng et al. (2007), who showed that $\mathrm{E}_{2}$ and EGF can induce the ERK pathway, leading to pER $\alpha$ Ser118, but is different from that of Joel et al. (1998b), who reported that $E_{2}$ is the most powerful stimulator of $p E R \alpha-$ Ser118 and it is independent of ERK. In addition, we also showed that $\mathrm{E}_{2}$-induced $\mathrm{pER} \alpha$-Ser167 is dependent of the PI3K/Akt signaling.

To date, the exact role of ER $\alpha$ phosphorylation at individual or multiple sites is underexplored. Functional roles in transcription, nuclear localization, dimerization, DNA binding, coactivator recruitment, ligand binding, RNA splicing, ER protein stability, regulation of other types of post-translational modifications, and cell growth/invasion have been demonstrated (Murphy et al. 2011). Results published in an earlier report indicated that IL6 can induce transcriptional activity of ER $\alpha$ in primary cultures of breast cancer epithelial cells, and this effect was blocked by treatment with the pure ER antagonist ZM 182780 or with an antibody directed against the signaling component of the IL6 receptor, gp130 (Speirs et al. 2000). In this study, we observed that IL6 can induce $\mathrm{ER} \alpha$ transactivation activity in a dose-dependent manner in A2780 cells, which are consistent with our previous findings obtained with another OVCA cell line, OVCAR-3 cells expressing both ER $\alpha$ and ER $\beta$ (Yang et al. 2009). Moreover, ER $\alpha$ transactivation activity was increased in IL6-overexpressing A2780 cells as compared with the corresponding control cells. Both exogenous and endogenous IL6-induced ER $\alpha$ transactivation activity in A2780 cells was blocked by the pure ER antagonist ICI 182780 and the MEK1/2 inhibitor PD98059 but not the PI3K-specific inhibitor wortmannin. These results provide evidence that IL6 can induce ER $\alpha$ transactivation activity in OVCA cells via ER-dependent MEK/ERK but not PI3K/Akt activation. This indicates that MEK/ERK-mediated pER $\alpha$-Ser118 increases ER binding to DNA to activate the ER pathway and thereby induce OVCA cells resistance to TAM, whereas PI3K/Akt-mediated pER $\alpha$-Ser167 does not in the presence of IL6. The latter is likely to activate the ER pathway to confer TAM resistance by other functional actions such as increasing recruitment of coactivator and interaction of ER and coactivator.

The results of previous studies in vivo and in vitro remain conflicting regarding whether $\mathrm{pER} \alpha$-Ser118 or $\mathrm{pER} \alpha$-Ser167 have an effect on TAM resistance (Mintz et al. 2008, Yamashita et al. 2008, Murphy et al. 2009, Guo et al. 2010, Motomura et al. 2010, Chen et al. 2013). Sarwar et al. (2006) demonstrated that $\mathrm{pER} \alpha$-Ser118 was elevated in tumor biopsies taken from patients who had relapsed following TAM treatment. Yamashita et al. (2008) revealed that a higher expression of $\mathrm{pER} \alpha$-Ser118 was a predictor of poorer survival. Recently, Chen et al. (2013) examined 104 patients with primary breast cancer who had received adjuvant TAM therapy and found that pER $\alpha$-Ser118, but not pER $\alpha$-Ser167, was significantly correlated with a shorter survival time and predicted breast cancer resistance to TAM. In contrast, Murphy et al. (2004) analyzed pER $\alpha-$ Ser118 by immunohistochemical staining in 117 breast cancer tissues and demonstrated that it was a marker of improved prognosis in patients treated with TAM. However, in the study by Murphy and colleagues the determination of ER $\alpha$-positive tumors was analyzed by ligand binding assay, not by immunohistochemical staining, and their patient inclusion criteria comprised axillary lymph node-negative and not only ER $\alpha$-positive tumors. Other studies have also demonstrated that $\mathrm{pER} \alpha$-Ser167 has an effect on the survival of breast cancer patients. Results of a study by Yamashita et al. (2008) indicated that a higher expression of pER $\alpha$-Ser167 was correlated with improved survival in ER-positive breast cancer cases. However, Guo et al. (2010) demonstrated that ER $\alpha$-Ser167 was phosphorylated by IKKe in vitro and in vivo, leading to the upregulation of cyclin D1 and resulting in TAM resistance. This discrepancy could be caused by differences in detection methods, cutoff points for diagnosis, inclusion criteria for the samples, and the treatment that the patients received following surgery. Unfortunately, the clinical relevance of $\mathrm{pER} \alpha$-Ser118 and/or $\mathrm{pER} \alpha$-Ser167 to TAM resistance in OVCA has not been reported thus far and further investigations are required to determine it.

In summary, we conclude that IL6 secreted by OVCA cells may contribute to the refractoriness of these cells to TAM via the crosstalk between ER and IL6-mediated intracellular signal transduction cascades such as MEK/ERK and PI3K/Akt pathways. Overexpression of IL6 not only plays an important role in OVCA progression but also promotes TAM resistance. Our results indicate that TAM-IL6-targeted adjunctive therapy may lead to a more effective intervention than TAM alone.

\section{Declaration of interest}

The authors declare that there is no conflict of interest that could be perceived as prejudicing the impartiality of the research reported.

\section{Funding}

This research was supported by grants from the National Natural Science Foundation of China (No. 81273520, 81471823), the Great Program of Science Foundation of Tianjin (No. 12JCZDJC26300, 12JCZDJC34700, 15JCYBJC28900) and the Great Program for Science and Technology in Logistics College of Chinese People's Armed Police Forces (No. WHZ201202, 2015ZXKF05, WHB201404, WHB201405, WHB201406).

Published by Bioscientifica Ltd. 
Author contribution statement

Y W, X L N, X Q G and J Y contributed equally to this work.

\section{Acknowledgements}

We thank Dr Gwendal Lazennec for providing the ERE2-TK-Luc plasmid.

\section{References}

Albanito L, Madeo A, Lappano R, Vivacqua A, Rago V, Carpino A, Oprea TI, Prossnitz ER, Musti AM, Andò S et al. 2007 G protein-coupled receptor 30 (GPR30) mediates gene expression changes and growth response to $17 \beta$-estradiol and selective GPR30 ligand G-1 in ovarian cancer cells. Cancer Research 67 1859-1866. (doi:10.1158/0008-5472.CAN-06-2909)

Arnold SF, Obourn JD, Jaffe H \& Notides AC 1995 Phosphorylation of the human estrogen receptor on tyrosine 537 in vivo and by src family tyrosine kinases in vitro. Molecular Endocrinology 9 24-33. (doi:10.1210/ mend.9.1.7539106)

Ascenzi P, Bocedi A \& Marino M 2006 Structure-function relationship of estrogen receptor $\alpha$ and $\beta$ : impact on human health. Molecular Aspects of Medicine 27 299-402. (doi:10.1016/j.mam.2006.07.001)

Beral V, Bull D, Green J \& Reeves G 2007 Ovarian cancer and hormone replacement therapy in the Million Women Study. Lancet 369 1703-1710. (doi:10.1016/S0140-6736(07)60534-0)

Campbell RA, Bhat-Nakshatri P, Patel NM, Constantinidou D, Ali S \& Nakshatri H 2001 Phosphatidylinositol 3-kinase/AKT-mediated activation of estrogen receptor $\alpha$ : a new model for anti-estrogen resistance. Journal of Biological Chemistry 276 9817-9824. (doi:10.1074/jbc.M010840200)

Chen M, Cui YK, Huang WH, Man K \& Zhang GJ 2013 Phosphorylation of estrogen receptor $\alpha$ at serine 118 is correlated with breast cancer resistance to tamoxifen. Oncology Letters 6 118-124. (doi:10.3892/ol. 2013.1324)

Cheng J, Zhang C \& Shapiro DJ 2007 A functional serine 118 phosphorylation site in estrogen receptor- $\alpha$ is required for down-regulation of gene expression by $17 \beta$-estradiol and 4-hydroxytamoxifen. Endocrinology 148 4634-4641. (doi:10.1210/en.2007-0148)

Duplessis TT, Williams CC, Hill SM \& Rowan BG 2011 Phosphorylation of estrogen receptor $\alpha$ at serine 118 directs recruitment of promoter complexes and gene-specific transcription. Endocrinology 152 2517-2526. (doi:10.1210/en.2010-1281)

Ge X, Guo R, Qiao Y, Zhang Y, Lei J, Wang X, Li L \& Hu D 2013 The G protein-coupled receptor GPR30 mediates the nontranscriptional effect of estrogen on the activation of PI3K/Akt pathway in endometrial cancer cells. International Journal of Gynecological Cancer 23 52-59. (doi:10.1097/IGC.0b013e31827912b8)

Gee JM, Robertson JF, Ellis IO \& Nicholson RI 2001 Phosphorylation of ERK1/2 mitogen-activated protein kinase is associated with poor response to anti-hormonal therapy and decreased patient survival in clinical breast cancer. International Journal of Cancer 95 247-254. (doi:10. 1002/1097-0215(20010720)95:4 < 247::AID-IJC1042> 3.0.CO;2-S)

Gee JM, Robertson JF, Gutteridge E, Ellis IO, Pinder SE, Rubini M \& Nicholson RI 2005 Epidermal growth factor receptor/HER2/insulin-like growth factor receptor signalling and oestrogen receptor activity in clinical breast cancer. Endocrine-Related Cancer 12 S99-S111. (doi:10.1677/erc.1.01005)

Glaros S, Atanaskova N, Zhao C, Skafar DF \& Reddy KB 2006 Activation function-1 domain of estrogen receptor regulates the agonistic and antagonistic actions of tamoxifen. Molecular Endocrinology 20 996-1008. (doi:10.1210/me.2005-0285)

Glud E, Kjaer SK, Thomsen BL, Høgdall C, Christensen L, Høgdall E, Bock JE $\&$ Blaakaer J 2004 Hormone therapy and the impact of estrogen intake on the risk of ovarian cancer. Archives of Internal Medicine $\mathbf{1 6 4}$ 2253-2259. (doi:10.1001/archinte.164.20.2253) Printed in Great Britain
Green KA \& Carroll JS 2007 Oestrogen-receptor-mediated transcription and the influence of co-factors and chromatin state. Nature Reviews. Cancer 7 713-722. (doi:10.1038/nrc2211)

Guo JP, Shu SK, Esposito NN, Coppola D, Koomen JM \& Cheng JQ 2010 IKK $\varepsilon$ phosphorylation of estrogen receptor $\alpha$ Ser-167 and contribution to tamoxifen resistance in breast cancer. Journal of Biological Chemistry 285 3676-3684. (doi:10.1074/jbc.M109.078212)

Hatch KD, Beecham JB, Blessing JA \& Creasman WT 1991 Responsiveness of patients with advanced ovarian carcinoma to tamoxifen. A Gynecologic Oncology Group study of second-line therapy in 105 patients. Cancer 68 269-271. (doi:10.1002/1097-0142(19910715) 68:2<269::AID-CNCR2820680209>3.0.CO;2-O)

Havrilesky LJ, McMahon CP, Lobenhofer EK, Whitaker R, Marks JR \& Berchuck A 2001 Relationship between expression of coactivators and corepressors of hormone receptors and resistance of ovarian cancers to growth regulation by steroid hormones. Journal of the Society for Gynecologic Investigation 8 104-113. (doi:10.1016/S10715576(01)00093-4)

Hirano T, Nakajima K \& Hibi M 1997 Signaling mechanisms through gp130: a model of the cytokine system. Cytokine \& Growth Factor Reviews 8 241-252. (doi:10.1016/S1359-6101(98)80005-1)

Jemal A, Siegel R, Ward E, Hao Y, Xu J, Thun MJ 2009 Cancer statistics 2009, CA: A Cancer Journal for Clinicians 59 225-249. (doi:10.3322/caac. 20006)

Joel PB, Smith J, Sturgill TW, Fisher TL, Blenis J \& Lannigan DA $1998 a$ pp90 ${ }^{\text {rsk1 }}$ regulates estrogen receptor-mediated transcription through phosphorylation of Ser-167. Molecular and Cellular Biology 18 1978-1984.

Joel PB, Traish AM \& Lannigan DA $1998 b$ Estradiol-induced phosphorylation of serine 118 in the estrogen receptor is independent of p42/p44 mitogen-activated protein kinase. Journal of Biological Chemistry 273 13317-13323. (doi:10.1074/jbc.273.21.13317)

Jordan VC \& O'Malley BW 2007 Selective estrogen-receptor modulators and antihormonal resistance in breast cancer. Journal of Clinical Oncology 25 5815-5824. (doi:10.1200/JCO.2007.11.3886)

Kato S, Endoh H, Masuhiro Y, Kitamoto T, Uchiyama S, Sasaki H, Masushige S, Gotoh Y, Nishida E, Kawashima H et al. 1995 Activation of the estrogen receptor through phosphorylation by mitogen-activated protein kinase. Science 270 1491-1494. (doi:10.1126/science.270.5241.1491)

Lacey JV Jr, Brinton LA, Leitzmann MF, Mouw T, Hollenbeck A, Schatzkin A \& Hartge P 2006 Menopausal hormone therapy and ovarian cancer risk in the National Institutes of Health-AARP Diet and Health Study Cohort. Journal of the National Cancer Institute 98 1397-1405. (doi:10.1093/jnci/djj375)

Lane D, Matte I, Rancourt C \& Piché A 2011 Prognostic significance of IL-6 and IL-8 ascites levels in ovarian cancer patients. BMC Cancer $\mathbf{1 1}$ 210-215. (doi:10.1186/1471-2407-11-210)

de Leeuw R, Neefjes J \& Michalides R 2011 A role for estrogen receptor phosphorylation in the resistance to tamoxifen. International Journal of Breast Cancer 2011 232435. (doi:10.4061/2011/232435)

Likhite VS, Stossi F, Kim K, Katzenellenbogen BS \& Katzenellenbogen JA 2006 Kinase-specific phosphorylation of the estrogen receptor changes receptor interactions with ligand, deoxyribonucleic acid, and coregulators associated with alterations in estrogen and tamoxifen activity. Molecular Endocrinology 20 3120-3132. (doi:10.1210/me.2006-0068)

Martin MB, Franke TF, Stoica GE, Chambon P, Katzenellenbogen BS, Stoica BA, McLemore MS, Olivo SE \& Stoica A 2000 A role for Akt in mediating the estrogenic functions of epidermal growth factor and insulin-like growth factor I. Endocrinology 141 4503-4511. (doi:10.1210/endo.141.12.7836)

Massarweh S \& Schiff R 2006 Resistance to endocrine therapy in breast cancer: exploiting estrogen receptor/growth factor signaling crosstalk. Endocrine-Related Cancer 13 S15-S24. (doi:10.1677/erc.1.01273)

Mintz PJ, Habib NA, Jones LJ, Giamas G, Lewis JS, Bowen RL, Coombes RC \& Stebbing J 2008 The phosphorylated membrane estrogen receptor and cytoplasmic signaling and apoptosis proteins in human breast cancer. Cancer 113 1489-1495. (doi:10.1002/cncr.23699) 
Moerkens M, Zhang Y, Wester L, van de Water B \& Meerman JH 2014 Epidermal growth factor receptor signalling in human breast cancer cells operates parallel to estrogen receptor $\alpha$ signalling and results in tamoxifen insensitive proliferation. BMC Cancer 14 283-298. (doi:10.1186/1471-2407-14-283)

Motomura K, Ishitobi M, Komoike Y, Koyama H, Nagase H, Inaji H \& Noguchi S 2010 Expression of estrogen receptor beta and phosphorylation of estrogen receptor alpha serine 167 correlate with progressionfree survival in patients with metastatic breast cancer treated with aromatase inhibitors. Oncology 79 55-61. (doi:10.1159/000319540)

Murphy LC, Niu Y, Snell L \& Watson P 2004 Phospho-serine-118 estrogen receptor- $\alpha$ expression is associated with better disease outcome in women treated with tamoxifen. Clinical Cancer Research 10 5902-5906. (doi:10.1158/1078-0432.CCR-04-0191)

Murphy LC, Skliris GP, Rowan BG, Al-Dhaheri M, Williams C, Penner C, Troup S, Begic S, Parisien M \& Watson PH 2009 The relevance of phosphorylated forms of estrogen receptor in human breast cancer in vivo. Journal of Steroid Biochemistry and Molecular Biology 114 90-95. (doi:10.1016/j.jsbmb.2009.01.017)

Murphy LC, Seekallu SV \& Watson PH 2011 Clinical significance of estrogen receptor phosphorylation. Endocrine-Related Cancer 18 R1-R14. (doi:10.1677/ERC-10-0070)

Nicholson RI, Hutcheson IR, Jones HE, Hiscox SE, Giles M, Taylor KM \& Gee JM 2007 Growth factor signalling in endocrine and anti-growth factor resistant breast cancer. Reviews in Endocrine \& Metabolic Disorders 8 241-253. (doi:10.1007/s11154-007-9033-5)

Nilsson MB, Langley RR \& Fidler IJ 2005 Interleukin-6, secreted by human ovarian carcinoma cells, is a potent proangiogenic cytokine. Cancer Research 65 10794-10800. (doi:10.1158/0008-5472.CAN-05-0623)

Normanno N, Campiglio M, Maiello MR, De Luca A, Mancino M, Gallo M, D'Alessio A \& Menard S 2008 Breast cancer cells with acquired resistance to the EGFR tyrosine kinase inhibitor gefitinib show persistent activation of MAPK signaling. Breast Cancer Research and Treatment 112 25-33. (doi:10.1007/s10549-007-9830-2)

Park KJ, Krishnan V, O'Malley BW, Yamamoto Y \& Gaynor RB 2005 Formation of an IKK $\alpha$-dependent transcription complex is required for estrogen receptor-mediated gene activation. Molecular Cell 18 71-82. (doi:10.1016/j.molcel.2005.03.006)

Penson RT, Kronish K, Duan Z, Feller AJ, Stark P, Cook SE, Duska LR, Fuller AF, Goodman AK, Nikrui N et al. 2000 Cytokines IL-1 $\beta$, IL-2, IL-6, IL-8, MCP-1, GM-CSF and TNF $\alpha$ in patients with epithelial ovarian cancer and their relationship to treatment with paclitaxel. International Journal of Gynecological Cancer 10 33-41. (doi:10.1046/j.1525-1438. 2000.00003.x)

Rabinovich A, Medina L, Piura B, Segal S \& Huleihel M 2007 Regulation of ovarian carcinoma SKOV-3 cell proliferation and secretion of MMPs by autocrine IL-6. Anticancer Research 27 267-272.

Rao BR \& Slotman BJ 1991 Endocrine factors in common epithelial ovarian cancer. Endocrine Reviews 12 14-26. (doi:10.1210/edrv-12-1-14)

Rossing MA, Cushing-Haugen KL, Wicklund KG, Doherty JA \& Weiss NS 2007 Menopausal hormone therapy and risk of epithelial ovarian cancer. Cancer Epidemiology, Biomarkers \& Prevention 16 2548-2556. (doi:10.1158/1055-9965.EPI-07-0550)

Sarwar N, Kim JS, Jiang J, Peston D, Sinnett HD, Madden P, Gee JM, Nicholson RI, Lykkesfeldt AE, Shousha S et al. 2006 Phosphorylation of $\mathrm{ER} \alpha$ at serine 118 in primary breast cancer and in tamoxifen-resistant tumours is indicative of a complex role for ER $\alpha$ phosphorylation in breast cancer progression. Endocrine-Related Cancer 13 851-861. (doi:10.1677/erc.1.01123)

Scambia G, Benedetti-Panici P, Ferrandina G, Distefano M, Salerno G, Romanini ME, Fagotti A \& Mancuso S 1995 Epidermal growth factor, oestrogen and progesterone receptor expression in primary ovarian cancer: correlation with clinical outcome and response to chemotherapy. British Journal of Cancer 72 361-366. (doi:10.1038/bjc.1995.339)

Schiff R, Massarweh S, Shou J \& Osborne CK 2003 Breast cancer endocrine resistance: how growth factor signaling and estrogen receptor coregulators modulate response. Clinical Cancer Research 9 447S-454S.

Silva J, Cavazos DA, Donzis E, Friedrichs WE, Marciniak R \& deGraffenried LA 2007 Akt-induced tamoxifen resistance is associated with altered FKHR regulation. Cancer Investigation 18 1-5. (doi:10.1080/07357900701513538)

Speirs V, Kerin MJ, Walton DS, Newton CJ, Desai SB \& Atkin SL 2000 Direct activation of oestrogen receptor- $\alpha$ by interleukin- 6 in primary cultures of breast cancer epithelial cells. British Journal of Cancer 82 1312-1316. (doi:10.1054/bjoc.1999.1097)

Syed V, Mlinski G, Mok SC \& Ho SM 2002 Reproductive hormone-induced, STAT3-mediated interleukin 6 action in normal and malignant human ovarian surface epithelial cells. Journal of the National Cancer Institute 94 617-629. (doi:10.1093/jnci/94.8.617)

Vendrell JA, Bieche I, Desmetz C, Badia E, Tozlu S, Nguyen C, Nicolas JC, Lidereau R \& Cohen PA 2005 Molecular changes associated with the agonist activity of hydroxy-tamoxifen and the hyper-response to estradiol in hydroxy-tamoxifen-resistant breast cancer cell lines. Endocrine-Related Cancer 12 75-92. (doi:10.1677/erc.1.00899)

Wang Y, Niu X, Qu Y, Wu J, Zhu Y, Sun W \& Li L 2010a Autocrine production of interleukin-6 confers cisplatin and paclitaxel resistance in ovarian cancer cells. Cancer Letters 295 110-123. (doi:10.1016/ j.canlet.2010.02.019)

Wang Y, Guo XQ, Niu XL, Wu J, Zhu YQ \& Mao LQ $2010 b$ Relationship of IL-6 and IL-8 secretion in epithelial ovarian cancer cell lines with their sensitivity to tamoxifen as well as MAPK, Akt and estrogen receptor phosphorylation. Xi Bao Yu Fen Zi Mian Yi Xue Za Zhi 26 21-24.

Wang Y, Li L, Guo X, Jin X, Sun W, Zhang X \& Xu RC 2012 Interleukin-6 signaling regulates anchorage-independent growth, proliferation, adhesion and invasion in human ovarian cancer cells. Cytokine $\mathbf{5 9}$ 228-236. (doi:10.1016/j.cyto.2012.04.020)

Wang Y, Qu Y, Zhang XL, Xing J, Niu XL, Chen X \& Li ZM 2014 Autocrine production of interleukin- 6 confers ovarian cancer cells resistance to tamoxifen via ER isoforms and SRC-1. Molecular and Cellular Endocrinology 382 791-803. (doi:10.1016/j.mce.2013.10.029)

Yamashita H, Nishio M, Kobayashi S, Ando Y, Sugiura H, Zhang Z, Hamaguchi M, Mita K, Fujii Y \& Iwase H 2005 Molecular changes associated with the agonist activity of hydroxy-tamoxifen and the hyper-response to estradiol in hydroxy-tamoxifen-resistant breast cancer cell lines. Breast Cancer Research 7 R753-R764. (doi:10.1186/ bcr1285)

Yamashita H, Nishio M, Toyama T, Sugiura H, Kondo N, Kobayashi S, Fujii Y \& Iwase H 2008 Low phosphorylation of estrogen receptor $\alpha(\mathrm{ER} \alpha)$ serine 118 and high phosphorylation of ER $\alpha$ serine 167 improve survival in ER-positive breast cancer. Endocrine-Related Cancer 15 755-763. (doi:10.1677/ERC-08-0078)

Yamnik RL, Digilova A, Davis DC, Brodt ZN, Murphy CJ \& Holz MK 2009 S6 kinase 1 regulates estrogen receptor $\alpha$ in control of breast cancer cell proliferation. Journal of Biological Chemistry 284 6361-6369. (doi:10.1074/jbc.M807532200)

Yan Y, Liu H, Wen H, Jiang X, Cao X, Zhang G \& Liu G 2013 The novel estrogen receptor GPER regulates the migration and invasion of ovarian cancer cells. Molecular and Cellular Biochemistry 378 1-7. (doi:10.1007/ s11010-013-1579-9)

Yang J, Wang Y, Gao Y, Shao J, Zhang XJ \& Yao Z 2009 Reciprocal regulation of $17 \beta$-estradiol, interleukin- 6 and interleukin- 8 during growth and progression of epithelial ovarian cancer. Cytokine $\mathbf{4 6}$ 382-391. (doi:10.1016/j.cyto.2009.03.013)

Received in final form 28 April 2015

Accepted 1 May 2015

Accepted Preprint published online 1 May 2015 http://jme.endocrinology-journals.org

DOI: 10.1530/JME-15-0011
(C) 2015 Society for Endocrinology Printed in Great Britain
Published by Bioscientifica Ltd 